www.jmscr.igmpublication.org

Impact Factor 3.79

Index Copernicus Value: 5.88

ISSN (e)-2347-176x ISSN (p) 2455-0450

crossref DOI: http://dx.doi.org/10.18535/jmscr/v4i1.37

Journal Of Medical Science And Clinical Research

\title{
Therapeutic Efficacy of Certain Unani Drugs in the Treatment of Chronic Rhino Sinusitis
}

\author{
Author
}

\section{Dr S J B Bokhari}

B Sc, M D, M Sc (Psy), D H A , PGDCA, Asst.Professor, P G Department of Moalijat (Gen.Med), Govt Nizamia Tibbi College, Charminar, Hyderabad

Email:drsjbbokhari@gmail.com,919885691909

\begin{abstract}
Chronic Rhino Sinusitis, Warm e Tajaweef e Anaf, (CRS) is a chronic disease that involves long-term inflammation of the nasal and para nasal sinus mucosa. Although commonly known as 'chronic sinusitis', the term 'chronic rhino sinusitis' is now being used more frequently, due to the involvement of the entire nasal and sinus passages. CRS causes not only physical suffering, but also impacts psychological well being. The incidence of CRS in southern Asian countries like India is 136,657,953 out of 1,065,070,607.Despite its widespread prevalence and substantial impact on the population, there is no satisfactory treatment. Unani system of medicine promises the cure. In this study forty patients suffering from CRS were enrolled to assess the efficacy of certain Unani drugs comprising of Safoof e Kakda Saenghi (Rhus succedanea Linn.) (Powder of Rhus succedanea Linn. with Honey) along with a decoction of Ustukhuddus (Lavendula Stoechas Linn.), Gul e Banafsha (Viola Odorata Linn.), Zofa e Khushk (Hyssopus officinalis Linn.). The powder was administered at a dose of 5 gram to be dissolved in the mouth by mixing with Honey, twice daily. and the decoction was prepared by soaking Ustukhuddus 5 grams, Gul e Banafsha 5 grams and Zofa e Khushk (Hyssopus officinalis Linn.) 5 gramsin $400 \mathrm{ml}$ of water and boiled till the water reduced to the half, then filtered and divided into two half doses given in the morning and evening before meals. The duration of the treatment varied from 45 to 90 days. The patients were clinically examined weekly and radiological tests were done periodically. Treatment was well tolerated with no side effects. The clinical efficacy was $80 \%$. Hence, this treatment could be recommended for the treatment of CRS.

Key Words: Unani Medicines, Nazla, Warm e Tajaweef e Anaf, CRS,RSTF, Kakda Saenghi, Ustukhuddus, Gul e Banafsha, Zofa e Khushk
\end{abstract}

\section{Clinical Definition}

The term chronic rhino sinusitis encompasses all inflammatory disorders of the nose and paranasal sinuses with a minimum duration of 12 weeks (RSTF-1996).

Demograph studies have suggested that women appear to be at higher risk. People living in the Midwest and south have a higher incidence of sinusitis than those in the northeast and west. People in higher income and educational groups appear to have a greater risk.

Etiology and Pathogenesis Chronic Rhinosinsuitis has a number of causes. It is often attributed to bacterial infection: both aerobic and anaerobic, as bacteria have been cultured from patients with CRS. It is not clear if bacteria 
causing infection are exposing the host to super antigens causing inflammatory response or are able to colonize due to pre existing pathology of the sinus mucosa (Meltzer et al-2004) and recent concept in the pathogenesis is colonization with fungi.

Currently, etiologic studies of sinusitis are increasingly focusing on ostiomeatal obstruction, allergies, polyps, occult and subtle immunodeficiency states, and dental diseases. Microorganisms are more often recognized as secondary invaders.Jyonouchi et al successfully induced chronic sinusitis in rabbits via intrasinus inoculation of Bacteroides fragilis. The authors subsequently identified immunoglobulin G (IgG) antibodies against this organism in the infected animals. In addition, IgG antibodies to anaerobic organisms have been observed in patients with chronic sinusitis. These findings further support a role for anaerobes in chronic sinusitis. Microbiologic studies of chronic sinusitis often show that the infection is polymicrobial, with isolation of 1-6 isolates per specimen. In some cases, the baseline chronic sinusitis worsens suddenly or causes new symptoms. This acute exacerbation of chronic sinusitis is often polymicrobial as well, with anaerobic bacteria predominating. Gram-negative facultative and aerobic bacteria, including $\mathrm{P}$ aeruginosa, are more often isolated in patients with chronic sinusitis who have undergone endoscopic sinus surgery.

Fungal involvement: The following fungi have been reported in samples obtained with endoscopy or sinus puncture in patients with chronic sinusitis: Aspergillus species, Cryptococcus neoformans, Candida species, Sporothrix schencki, Alternaria species.

The following conditions and risk factors predispose patients to the development of chronic sinusitis: Anatomic abnormalities of the ostiomeatal complex (e.g., septal deviation, concha bullosa, deviation of uncinate process, Haller cells), Allergic rhinitis, Aspirin sensitivity, Asthma, Nasal polyps, Nonallergic rhinitis (e.g., vasomotor rhinitis, rhinitis medicamentosa, cocaine abuse), Defects in mucociliary clearance, Nasotracheal intubation, Nasogastric intubation, Hormonal (e.g., puberty, pregnancy, oral contraception), Obstruction by tumor, Immunologic disorders (e.g., common variable immunodeficiency, immunoglobulin A [IgA] deficiency, IgG subclass deficiency, AIDS), Cystic fibrosis Primary ciliary dyskinesia, Kartagener syndrome, Wegener Granulomatosis, Repeated viral upper respiratory tract infections, Smoking, Environmental irritants and pollutants, Gastroeosophageal refluxes (GERD). (The reflux of gastric contents may play a contributing role in some cases of CRS; this relationship still needs to be better defined), Periodontitis/significant dental diseases, Systemic diseases i. e, granulomatosis with polyangiitis (Wegener granulomatosis), Churg-Strauss vasculitis, sarcoidosis.

Review of Literature: The Unani system of medicine is based on Humoral Theory proposed by Hippocrates (460 B.C.) According to Hippocrates there are four Humours i.e., Dam (Blood) which is Hot and Moist, Balgham (Phlegm) which is cold and moist, Safra (Yellow Bile) which is hot and dry and Black Bile (Sauda) which is cold and dry. When the specific equilibrium of Akhlat (Huomours) is altered and the temperament of the internal environment is altered, the disease is developed. (Hippocrates). Avicenna, Nafisi, Abul Hasan Raban Tabri and others described the abnormal phlegm or cold moist phlegm as one of the causes of phlegmatic diseases Also there is a defense mechanism in human body known as TABIYAT-EMUDABBIR-E-BADAN. Tabiyat may be defined as the sum total of the structural, functional and psychological factors of the individual which maintains equilibrium/homoeostasis, and when Tabiyat becomes weak, diseases come. Galen described three stages of health: Sehath (health), Marz (Disease) and La sehha o La marz (neither health nor disease). And these stages are dependent on Asbab e Sabiqa, Asbab e Vasila and Asbab e Badiya. In Moalijat e Buqratiya and in 
Shar he asbab, it is mentioned that improper food, imbalanced food, general weakness, and decrease in the immunity, and in the persons who do not observe the rules of Asbab e Sitta Zarooriya (six essential factors of life), are exposed to the diseases. Avicenna described Unhygienic environment, Imbalanced diet and obstruction in passages as the cause of Ufoonat (infection) which results in inflammation.

There is no separate description of CRS in Unani Literature. The Clinical features of CRS bears resemblance with Nazla e Bard.Nazla is well defined and understood phenomenon of Arabs. Great ancient physicians like Ibn e Sena, Zakaria Razi, Ibn e Rushd have described the role of Intrinsic as well as Extrinsic factors in the development of the disease. Hakim Akber Arzani described that the waste products of the brain are secreted towards the respiratory system as Nazla, when they are secreted via the nose it is termed as Zukam. They have also hypothesized the role of homeostatic system in providing the stimulus for the production of excessive Phlegm; In this regard they have mentioned that exposure to cold conditions in which homeostatic system is involved leads to excessive production of phlegm. They defined sinusitis in terms of Nazla wa Zukam. Unani physicians have also mentioned the role of local irritants which produce local change in temperament and involvement of gastro intestinal tract in the development of Nazla. (16, 17,). They have also hypothesized the role of intrinsic temperament in the development of Nazla, they stated that when the cause is not extrinsic, the phlegmatic people are more prone to develop sinusitis (18).Unani physicians divided Nazla into two: Ha'ar and Barid. Nazla Barid occurs in persons with cold temperament or when their temperament gets altered due to excessive cold or humid environment. / Poor nourishment / seasonal changes. Patients with cold temperament have a positive history of Nasal discharge, Nasal obstruction, voice change and feeling of heaviness in the forehead, which corresponds to the symptoms of CRS
The clinical features mentioned are: nazla, lassitude, irritation, heaviness of the head and eyes, sneezing, dryness of throat, headache, etc.

Diagnosis: In addition to history, physical signs are important in the diagnosis. The RSTF has developed a list of major and minor criteria (signs and symptoms) to aid in diagnosis of chronic rhino sinusitis. The major criteria include Facial Pain/Pressure, Nasal obstruction, Nasal discharge, Hyposmia/Anosmia, Purulence in nasal cavity on examination, and Fever, in acute case only. The minor criteria include Headache, Fever, Halitosis, Fatigue, Dental pain, Cough, and Ear pain/fullness. Anterior rhinoscopy is a noninvasive means of viewing the nasal mucosa. However, it is difficult to view beyond the anterior portion of the nasal passages, even after administration of topical decongestants. Nasal endoscopy, although more invasive, is a preferable method for obtaining a magnified view of the nasal mucosa, turbinates, and interior of the nasal airway in the preoperative and post-surgical patient. Endoscopy aids in assessing the integrity of the mucosa, as well as directly seeing mucosal changes, polyps, crusting, and/or discharge. Cultures can also be obtained endoscopically. Discolored nasal discharge, polyps, or polypoid swelling seen with anterior rhinoscopy or endoscopy, and edema or erythema of the middle meatus or ethmoid bulla seen on endoscopy, are consistent with CRS. If edema, erythema, or granulation tissue do not extend to the middle meatus or ethmoid bulla, radiologic imaging is necessary to view the sinuses and to make or confirm the diagnosis of CRS.Imaging modalities are often necessary in CRS, especially in patients with refractory or recurrent disease. Plain film Xrays have not been proven to be useful in CRS. Computed tomography (CT) scanning is the imaging method of choice. Coronal CT scans are indicated in patients with recurrent sinusitis or CRS in order to properly consider treatment options and sequence the steps in the evaluation. Mucosal thickening, bony changes, or air-fluid levels seen on CT are consistent with CRS. There 
are instances when lateral or axial imaging is required to determine the extent of the disease process. Magnetic Resonance imaging (MRI) is not recommended for diagnosis of CRS due to its lack of specificity; however, it is superior to CT for differentiation between infectious (bacterial or viral) inflammation and fungal concretions as well as in detecting malignancies. MRI can also detect extension of disease beyond paranasal sinuses into the orbital region and intracranial compartment

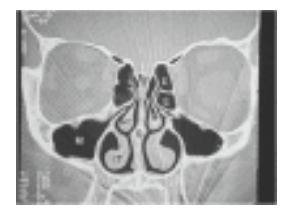

CT scan of normal sinuses

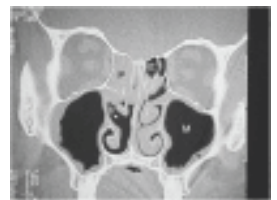

CT scan of sinuses with sinusitis

Laboratory tests, such as nasal cytology, nasal biopsy, and hematologic analyses are not necessary for the clinical diagnosis of CRS. They can aid in determining whether other conditions are present, such as acute bacterial infection or allergy, or more serious conditions such as cystic fibrosis, ciliary dysfunction, or various immune deficiencies

\section{Principles of treatment:}

1. Source of Cold should be reduced.

2. The madda to be removed.

In Unani system, the treatment is both local and general. Local treatment consists of repeated inhalations which liquefy the viscid humours which are clogged in the sinuses. The general treatment consists of moderating the altered humours and correction of altered temperament. The ma'adda is to be liquefied for easy elimination. This should be done after maturation In Nazla Barid hot medications or application give relief to the symptoms
Materials and Methods

Aim of Study:

1. To propagate Unani drugs as best alternative

2. To assess the efficacy of drugs

3. To minimize the surgical requirement

Selection of Drugs: The drugs are selected according to their properties, actions and which are mentioned in Unani Classics.

Study Design: This was a randomized non comparative trial performed in $\mathrm{O} \mathrm{P} \mathrm{D}$, designed to demonstrate the clinical efficacy of Unani drugs in the treatment of CRS. Written informed consent was obtained from all the participating patients.

Inclusion Criteria: Who satisfied Diagnostic Criteria

\section{Exclusion Criteria:}

1. Hypersensitivity to any of the herbal drugs

2. Complicated sinusitis

3. Abnormality of sinus impairing drainage

4. History of sinus surgery within three months

5. History of antibiotic therapy within 15 days

6. Renal insufficiency

7. Pregnancy and lactation

8. Deviated Nasal Septum

9. Tumors

10. Orbital Cellulitis

11. Meningitis

Diagnostic Criteria: CRS is probable if the patient has two or more major factors or one major and two or more minor factors for more than 12 weeks..

Treatment and Compliance: Patients were given Safoof e Kakda Saenghi (Rhus succedanea Linn.) (Powder of Rhus succedanea Linn. mixed with Honey), along with a decoction of Ustukhuddus (Lavendula Stoechas Linn.), Gul e Banafsha (Viola Odorata Linn.), Zofa e Khushk (Hyssopus officinalis Linn.). The powder was administered at a dose of 5 grams to be dissolved in the mouth by mixing with Honey, twice daily. And the decoction was prepared by soaking Ustukhuddus 
(Lavendula Stoechas Linn.) 5 grams, Gul e Banafsha (Viola Odorata Linn.) 5 grams and Zofa e Khushk (Hyssopus officinalis Linn.) 5grams in $400 \mathrm{ml}$ of water and boiled till the water is reduced to the half. Then filtered and divided into two half doses given in the morning and evening before meals. The duration of the treatment varied from 45 to 90 days. The patients were clinically examined weekly and radiological tests were done periodically. During this period patients were adviced not to take other systemic antibiotics, antihistamines and decongestants. Treatment was well tolerated with no side effects.

Study Procedure: The assessment of patients was conducted 4 times:

- Within 48 hours of dosing

- Day 7 to 15 day

- Day 30 to 45 days

- Day 45 to 90 days

At the baseline, after subjects provided written consent, the criteria were reviewed. The demographic, medical history and drug history was collected. A targeted physical examination, clinical assessment was done. X ray P N S and other routine tests performed. At the end of the study, X ray PNS was taken and compared with baseline.

Criteria for evaluation: Clinical response was classified into three categories:

Clinical Success: Resolution or improvement in signs and symptoms with clear $\mathrm{X}$ ray $\mathrm{P} \mathrm{N} \mathrm{S}$, without any additional therapy.

Failure: Persistence and worsening of signs and symptoms

Unable to determine: Not taken medicines or received other drugs or lack up follow up.

\section{Results and discussion}

Disposition of the Patients: 40 patients completed the study as per protocol.8 patients did not have proper follow up or did not tolerate the drugs due to its bitterness or the make of drugs.
Clinical Findings: The most frequently noted symptoms of sinusitis were nasal discharge (85\%), nasal obstruction $(80 \%)$, Facial pain $(70 \%)$, Anosmia/Hyposmia (10\%).

In $65 \%$ of the patients, maxillary sinuses were involved, and in $25 \%$ of the patients, maxillary and frontal sinuses were involved, and in $10 \%$ of the patients it was Pansinusitis.

In $80 \%$ of the cases $X$ ray PNS showed opacity in the sinuses.

Therapeutic Efficacy: Data of the patients showed significant improvement from second week onwards. 25 patients were completely free from symptoms with 45 days of treatment. 7 patients didn't have much improvement in 45 days but after completion of the trial, they showed good response and the remaining 8 patients didn't show proper response or not followed or didn't take medicines.

At the end point, the radiological examination showed no opacity or haziness in the sinus which suggested good sinus drainage and proper sinus ventilation. Patients were also adviced to report in the winter or rainy season, if the symptoms have recurred. None of them reported

Safety Evaluation: No adverse effects or side effects were found during the study

Table No.1 Table showing Symptoms found (Major Criteria) in the 40 cases

\begin{tabular}{|l|c|c|}
\hline Symptoms & No. of Patients & $\%$ \\
\hline Facial Pain/Pressure & 28 & 70 \\
\hline Nasal Obstruction & 32 & 80 \\
\hline Nasal Discharge & 34 & 85 \\
\hline Hyposmia/Anosmia & 04 & 10 \\
\hline Purulence in the cavity & Nil & Nil \\
\hline Fever & Nil & Nil \\
\hline
\end{tabular}

Table No.2 Showing distribution of 40 cases according to Radiological findings

\begin{tabular}{|l|c|c|}
\hline Type of Sinusitis & No. Of Patients & $\%$ \\
\hline Maxillary & 26 & 65 \\
\hline Maxillary \& Frontal & 10 & 25 \\
\hline Pansinusitis & 04 & 10 \\
\hline Total & 40 & 100 \\
\hline
\end{tabular}




\section{JMSCR Vol||04||Issue||01||Page 9001-9006||January}

Table No, 3 Table showing Therapeutic Efficacy of the drugs used

\begin{tabular}{|l|l|c|c|}
\hline Sl.No & Therapeutic Evaluation & No. of Patients & $\%$ \\
\hline 1. & Clinical Success & 32 & 80 \\
\hline 2. & Failure & Nil & Nil \\
\hline 3. & Unable to Determine & 8 & 20 \\
\hline Total & & 40 & 100 \\
\hline
\end{tabular}

Table No-4 Table showing Age distribution in studied cases

\begin{tabular}{|l|c|c|}
\hline Age in Years & No. of Patients & $\%$ \\
\hline $14-24$ & 12 & 30 \\
\hline $25-34$ & 09 & 22.5 \\
\hline $35-54$ & 16 & 40 \\
\hline Above 55 & 03 & 7.5 \\
\hline Total & 40 & 100 \\
\hline
\end{tabular}

Table No-5 Table showing Sex Index

\begin{tabular}{|l|l|l|}
\hline Sex & No. of Patients & $\%$ \\
\hline Male & 16 & 40 \\
\hline Female & 24 & 60 \\
\hline Total & 40 & 100 \\
\hline
\end{tabular}

Table No.-6 Table showing Duration of Present illness

\begin{tabular}{|l|c|c|}
\hline Duration & No. of Patients & $\%$ \\
\hline 6 months to 1year & 19 & 47.5 \\
\hline 1Year to 2 years & 15 & 37.5 \\
\hline More than 2 Years & 06 & 15 \\
\hline Total & 40 & 100 \\
\hline
\end{tabular}

\section{Discussion}

CRS is a chronic disease having multifactorial etiology which causes not only physical suffering but also impacts psychological well being. There is no separate description of CRS in Unani literature. The clinical features of CRS bear resemblance with Nazla-e-Barid. This study was carried out to assess the Therapeutic efficacy of Unani drugs in treating the CRS. The etiological factors described by the modern physicians includes recurrent attacks of cold, infections, intake of cold diets, unhygienic conditions, swimming etc.. The clinical features found are frequent attacks of cold, headache, change in voice, post nasal drip. (6\&7). Unani physicians described the Cold weather, unhygienic conditions etc., which alters the temperament and equilibrium of humours $(1,2 \& 3)$. The medicines selected were highly claimed and frequently mentioned in Unani Classics. The aim is to expel the dominant phlegmatic humor which is accumulated and to correct the altered temperament .Patients were observed for 90 days and it is found that the response was $80 \%$. No recurrence was noted in the follow up period and no adverse reactions were seen.

\section{Conclusion}

This study suggests that this treatment could be recommended for CRS

\section{References}

1. Avicenna,"Alqanoon fil Tib" Urdu translation by Ghulam Hussain, VoI and III, 105,130,268,278.

2. Azam Mohammed "Qarabadeen-e-Azam", 212,273and 383,

3. Zakaria Razi,"Al Havi,Vol III:Amraz-eAnaf,103

4. Kabeeruddin,'Tarjuma-e-Kabeer,Vol I,221,230,

5. Nadkarni,'Indian Matreria Medica," Vol I, 830,834

6. Hall \& Colman, "Diseases of Nose, Throat\&Ear,7-24

7. Mohammed Maqbool, "Text Book of ENT'(2000),129-136

8. Ishtiaq Ahmed, "Introduction to Al Umoor AlTabyiya, 5,17,26,

9. Kabeeruddin, "Kulyat e Nafisi” 62,63,65

10. Md.Akbar Azam, "Tibb e Akbari” 48

11. Mohammed Kabeeruddin, "Al Akseer", VolI, Nazla o Zukam,362,375

12. Kabeeruddin, Makhzan ul Mufarradat, VolII,136,137,218,219,321

13. Abul Hhasan Ali bin Sahal Raban tabri,'Firdous ul hikmat,Faizal' publications Deoband178-9

14. Ajmal khan , Haziq, beesweensadi book depot, new delhi,73-75

15. Ghulam Jeelani , Maghzanul ilaj, vol I, 169-171, idara e kitabusshifa 